\title{
Información: utopía y realidad de la Bibliotecología
}

\author{
Sebastiao de Souza \\ Departamento de Ciencia de la \\ Información y Documentación, \\ Universidad de Brasília, Campus \\ Universitario, Asa Norte. Brasília \\ D.F., Brasil. \\ E-mail:souza@apis.com.br
}

\section{RESUMEN}

$\boldsymbol{E}_{1}$ artículo presenta los tres grandes problemas de las ciencias y también de la biblotecología : epistemológico, teleológico y de identidad; discurre sobre algunos conceptos filosóficos de la información, sus relaciones con la sociedad, el desarrollo y la ideología, concluyendo que todo es información.

\section{ABSTRACT}

$\boldsymbol{P}_{\text {resent three great problems of science and also of the Library Science: }}$ episthemological, teological and of indentity; discuss about any philosophical concepts of information, their relations with the society, the development and the ideology, concluding that all is information.

\section{INTRODUCCIÓN}

P ara que una área del conocimiento pueda llamarse de ciencia, se deben cumplir algunas exigencias indispensables, y se tienen que resolver satisfactoriamente tres grandes problemas: el problema epistemológico, el teleológico y de la identidad.

El problema epistemológico comprende los estudios teóricos y filosóficos, los conceptos, la terminología explícita sobre la ciencia en particular; comprende también los estudios de su interdisciplinariedad y metodología, y principalmente, el estudio de su objeto. Este último será tema del presente trabajo.

El problema teleológico se refiere a sus finalidades y metas. Incluye también estudios sobre la formación profesional y sus funciones sociales, culturales, educativas, políticas e informacionales. Es una de las más importantes prerrogativas de la ciencia, pues, todo lo demás resulta de él. Todas las ciencias son hechas para beneficio de la sociedad, siempre teniendo en cuenta que cada ciencia tiene sus finalidades específicas.
El problema de la identidad es el resultado de los otros dos, porque el problema epistemológico establece la imagen científica y teórica de la ciencia, y el problema teológico, su imagen social.

La bibliotecología, como las otras ciencias, enfrenta igualmente estos tres problemas; se puede decir que ella no tiene una imagen científica muy fuerte, porque su situación epistemológica no es muy consistente. Ejemplo de esta situación es el nombre de la misma ciencia: Librarianship, en Inglaterra; Library Science e Information Science, en los Estados Unidos; Biblioteconomía, en Brasil, Portugal, Italia y Francia; Bibliología y Bibliotecología, en España y en los países latinoamericanos; Ciencias de la Documentación, también en España; Informática, en Rusia, que corresponde a la Ciencia de la Información, sin mencionar otros nombres como Epistemología Social, Informología, Informatología, etcétera. Sin embargo, el objeto sin el objetivo no es nadie; este último es el que dará todo el sentido al contexto bibliotecológico. De nada vale ir a fondo en altas teorías filosóficas, sin que la finalidad específica de la Bibliotecología no hubiera sido puesta. Es la finalidad la que regula el destino de las cosas, de los seres y de las ciencias. Las finalidades de la bibliotecología, en la teoría, son espléndidas: tenemos que servir a la sociedad, tenemos que reducir la angustia de los usuarios por las informaciones, tenemos que hacer llegar la información para todos los segmentos sociales. Pero, en la práctica, no es así: seleccionamos la información; las mejores bibliotecas son las especializadas y universitarias, nos olvidamos de la población necesitada y pobre, porque nuestro compromiso mayor es con la clase media y con la clase dominante.

Toda esta composición tridimensional de la bibliotecología no puede desvincularse de otro factor: el histórico, ya que, para entender los tres problemas, es necesario estudiar la inserción de dicha ciencia en el contexto socio-económico-político-cultural del país y del mundo, para que se pueda ver, con claridad, el signifi- 


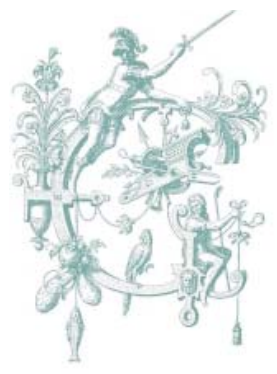

\section{Desde el punto de vista epistemológico, el campo de los fenómenos de la bibliotecología es la información y el tratamiento que hacemos de ella, las finalidades para la cual la destinamos, es su objeto específico de estudio.}

cado de cada acción bibliotecológica, con el pasar de los tiempos.

Una profunda reflexión sobre estos puntos, nos llevará, necesariamente, a profundizar nuestros estudios sobre la filosofía de la bibliotecología y establecer la configuración de su identidad científica y social; y éstos llevarán también a la formación de una visión global sobre la praxis bibliotecológica, de donde deberá surgir el modus vivendi del bibliotecólogo, la realidad de la profesión, las metas que se deben seguir y sus perspectivas para el futuro.

Para superar estas deficiencias tenemos que incrementar nuestros estudios sobre la información y su terminología y definir mejor su interdisciplinariedad; y al mismo tiempo, la bibliotecología tiene que ampliarse horizontalmente procurando llevar la información hasta la sociedad.

\section{LA INFORMACIÓN}

Filosóficamente decimos que la información es el objeto material y formal de la bibliotecología. Por objeto material entendemos toda la información real y potencial; toda la información conocida y todas las que vengan a ser conocidas; objeto formal de la bibliotecología es la información registrada en cualquier tipo de soporte físico: sea libro, periódico, disco, etcétera.

De esta manera, la información, generalmente, es objeto de todas las ciencias; pero, es el objeto específico de algunas ciencias, como la Comunicación, Archivística, el Procesamiento de Datos, la Bibliotecología y otras más. La diferencia es que cada ciencia trata la información en un aspecto particular. La información es un objeto interdisciplinar, es el elemento de unificación de las ciencias.

Etimológicamente, la palabra información (informare, en latín) es el acto o el efecto de informar; informarse es la transmisión de conocimientos; la investigación es crear una idea o nociones y dar la forma para alguna cosa.

La información puede ser comparada con la masilla de amoldar que, en las manos de los niños, sirve para formar lo que quieran; la información es así.

Según Shera, información es un término utilizado con muchos significados y para cada uno de ellos existe una definición.
En el sentido genérico, información es todo lo que es transmitido por el acto o procedimiento de la comunicación, ya sea un mensaje, una señal o un estímulo. En un sentido más estricto, la información pasa a ser casi un sinónimo de adquisición de conocimientos. Éste es el instrumental que le da su valor social.

Existen diferentes tipos de información, pero lo que más interesa es la información científica y tecnológica, sin olvidar la información factual y numérica.

Según Dereck Solla Price, la ciencia y tecnología crecen en razón del $7 \%$ al año independiente de los factores históricos, políticos, económicos y otras fuerzas que se puedan considerar como influenciadores en este contexto.

Seguramente que el crecimiento del $7 \%$ al año es muy diferente en los países desarrollados, en comparación con los países en desarrollo. Es lo mismo que comparar el aumento del salario de $30 \%$ para quien gana 300 dólares con aquel otro que gana 30000 dólares.

Este crecimiento se refiere, también, a las ciencias, que tienen el mismo índice de elevación, pero con resultados diferentes. En la actualidad, los hombres, las instituciones y los países luchan por el dominio de la información en el mundo, ya que la información se ha convertido en un bien de consumo muy valioso. Las multinacionales que dominan la economía mundial quieren de la misma manera el dominio de la información, porque la información es poder. Ellas no quieren hacer ciencia, quieren lucros y la industria de la información es el sector cuaternario de la economía mundial que está produciendo muchos lucros, en comparación con los otros tres sectores.

Desde el punto de vista epistemológico, el campo de los fenómenos de la bibliotecología es la información y el tratamiento que hacemos de ella, las finalidades para la cual la destinamos, es su objeto específico de estudio. Según Fernandes, los parámetros más básicos para conceptuarse o caracterizarse una ciencia es la localización del campo de los fenómenos, por lo que se interesa "para donde se mira" y la localización del objeto de estudio "cómo mirarlos".

De esta manera, la información es conocimiento y conocer es un proceso inherente a la criatura humana. Los animales proceden por instinto, hacen siempre las 


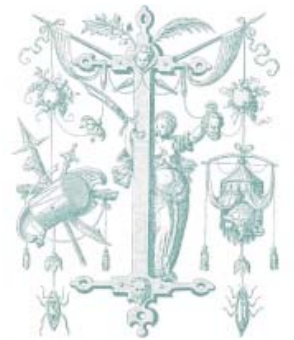

Desde el punto de vista epistemológico, el campo de los fenómenos de la bibliotecología es la información y el tratamiento que hacemos de ella, las finalidades para la cual la destinamos, es su objeto específico de estudio

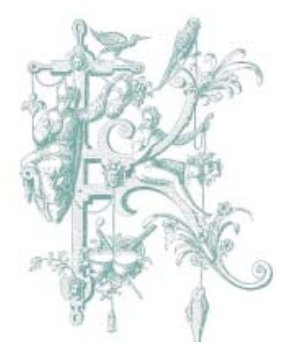

mismas cosas. Todo lo que es cognoscible es parte del conocimiento; aún más, lo cognoscible solamente pasa a ser conocimiento en el momento en que se hace conocido; es decir, en el momento en que se hace información.

En el principio, el conocimiento no era dividido, era una sola cosa. El hombre con su incapacidad de globalizar, fue que creó los diversos tipos de conocimiento. Conocimiento es saber y saber es información, objeto de la bibliotecología.

Otros autores dicen que la información, como objeto de estudio de la bibliotecología, debe ser tratada en un contexto sistemático y su valor debe ser extraído si consideramos la totalidad de la organización.

Shera prefiere resaltar las finalidades de la bibliotecología, llamándola "Epistemología social", o sea, el conocimiento al servicio de la sociedad. Mientras tanto, el mundo capitalista está muy ocupado con el pragmatismo utilitarista, para comprender todo el significado social de la información. Pero, la información será el elemento más importante en la construcción del futuro de la sociedad mundial.

\section{LA INFORMACIÓN Y LA SOCIEDAD}

Podemos decir que, actualmente, nuestra sociedad está sostenida por la siguiente trilogía: el desarrollo, la información y la ideología. La ideología depende de la información y del desarrollo, pero también dirige y controla la información y el desarrollo, haciendo que ellos sean sus dependientes.

La ideología, refiriéndose al poder dominante, es el ocultamiento de la realidad para justificar las condiciones de explotación y la dominación, lo que hace que éstas sean verdaderas y justas, en apariencia.

La ideología ejerce un predominio indirecto en todo, y muchas veces, sin querer, estamos alimentando la ideología del poder dominante; ella se oculta en la realidad, de tal manera que sufrimos su influencia sin sentir.

En un sentido amplio, la ideología es un conjunto de ideas, principios y valores que expresan una determinada visión del mundo, orientando una forma de acción, especialmente una práctica política. La ideología siempre fue el recurso de los poderosos para gobernar y oprimir a los pueblos.
Para la ideología, la información tiene un valor sin límites, porque ella es el sustrato que alimenta la ideología y el desarrollo de una nación, de un estado o de una organización.

Por otro lado, la información es la fuerza propulsora del desarrollo de la sociedad. La información, objeto formal de la bibliotecología, no puede ser tratada simplemente desde el punto de vista del pragmatismo utilitarista. La información es mucho más que eso; ella es un elemento de transformación.

Este enfoque proporciona a la bibliotecología, su verdadero sentido, revela su dinamismo, presta a ella foros científicos, pues, la ciencia es progreso, es transformación, es vida.

Esta característica de la información, como elemento transformador, es la que lleva al profesional a estudiar, a reciclarse, a actualizarse y a investigar. En la medida en que él estuviera más actualizado e inserido en el contexto de su mundo y de su profesión, sería más útil a la sociedad, como instrumento transformador de la misma. De ahí se deduce su importancia social.

El mundo actual, tan carente y angustiado por informaciones cada vez más rápidas y precisas, hace del bibliotecólogo un profesional necesario y de la bibliotecología una profesión siempre más valorada.

\section{CONCLUSIÓN}

Anderla, en su libro La información en 1985 dice que existe la necesidad de tener un concepto global de la información, incluyendo "edición, prensa, radiodifusión, bibliotecas, correos, teléfonos, así como gran parte de la enseñanza, de los servicios gubernamentales y administrativos, de las actividades industriales, comerciales y profesionales". La información invade todo; abraza todo e incorpora todo.

Por esto podemos deducir que el objeto de la bibliotecología es muy amplio y difícil de ser controlado. Ella merece estudios más profundos y expandir sus teorías.

Éste es el gran problema actual de la bibliotecología, es la delimitación de su objeto de estudio; y ésta trae una serie de problemas, que tiene que resolver, para mantenerse en el seno de la gran familia científica. 
Parafraseando a Anderla, si la información es todo, la bibliotecología también es todo. Bibliotecología es comunicación, es información; es casi una síntesis de todas las otras profesiones; es ligarse con todas ellas; bibliotecología es cultura, servicio comunitario; es el interés por la difusión de la información, independiente de raza, color, profesión, edad, religión, condición social, etcétera; bibliotecología es saber entregarse a los otros, es sonreír cuando nos gustaría llorar; bibliotecología es, antes de todo, un estado de espíritu, una disposición perenne de siempre querer saber más, para poder informar cada vez mejor; bibliotecología es una forma de elevarse y elevar el mundo; es colocar la información encima de todo, encima de nuestros intereses personales, encima del mismo sueldo que recibimos; bibliotecología es creer en el valor social de la información y en su universalidad; bibliotecología es salir de nuestras rutinas documentales y seguir hacia la creatividad; es dejar de lamentaciones que provocan el desánimo y caminar hacia la acción, hacia el trabajo, hacia la sublime misión de informar todo a todos y de la mejor manera posible. Éstas son las metas de la bibliotecología, o quizá, su utopía, pues cuanto mayor fuera la concientización del bibliotecólogo, de que todo es información, mejores servicios se le ofrecerían a la sociedad.

Vivimos, como ya preconizaba McLuhan, en una sociedad de informa- ción globalizada. Tenemos la impresión de que, ahora, con Internet, sabremos todo, pero, no es así; es cierto que Internet se caracteriza por una abertura más sensible hacia la democratización de la información. Pero, la información automatizada continúa siendo una posibilidad para pocos y una gran utopía para muchos. Como dice J. Navarro "no existen caminos listos; cada persona hace su propio camino en la medida que va andando", estamos muy lejos de comprender perfectamente las palabras de Ortega y Gasset, comparando al bibliotecólogo con un filtro puesto entre la corriente de los conocimientos y al usuario de la información.

\section{BIBLIOGRAFÍA}

ANDERLA, Georges. A informaçao en 1985. Río de Janeiro: IBICT, 1979. 210p.

CAVALCANTI, Cordélia Robalinho y Murilo Bastos da Cunha. Dicionário de ciencia da informaçao. Brasilia: UnD/CID, 1996. (Ediçao preliminar)

CARON, Gilles. "Vers une philosophie de la bibliothéconomie". En Documentation et bibliotheques, p. 187-196, dec. 1975.

FERNANDES, Geni Chavez. "O objeto de estudo da ciencia da informaçao".En Informare, Río de Janeiro, Vol.1, No.1, p. 25-30, jan./jun. 1995.

JANIASSU, Hilton y Danilo Marcondes. Dicionário básico de filosofia. Río de Janeiro: Jorge Zahar, 1990. 265p.

MUKHERJEE, A. K. “The philosophy of Librarianship”. En Librarianship; its philosophy and history. Bombay: Asia Publ. House, 1966.

SHERA, Jesse H. "An epistemological foundations for Library Science". En The foundations of education for Librarianship. New York: Becker and Hayes, 1972. p. 109-134.

SOUZA, Sebastiao de. Dimensoes atuais da biblioteconomia no Brasil: um estudo através de suas tendencias. Joao Pessoa: UFPB, 1987. 160 p. il. (Dissertaçao de Mestrado).

"Fundamentos filosoficos da biblioteconomía". En Bibliotecon. Brasilia, Vol. 14, No. 2, p. 189-196, jul./dez. 1986. 